\title{
Bilateral multiple cavernous haemangiomas of the orbit
}

\author{
Timothy J Sullivan, G William Aylward, John E Wright, Ivan F Moseley, Alec Garner
}

\begin{abstract}
Orbital cavernous haemangioma, a common orbital tumour, is usually single and unilateral. We report the first case of histologically confirmed bilateral multiple cavernous haemangiomas of the orbit.

(Brf Ophthalmol 1992; 76: 627-629)
\end{abstract}

Orbital cavernous haemangioma typically occurs as a slow growing well circumscribed lesion in the lateral part of the middle third of the orbit.' Patients most commonly present with slowly progressive painless proptosis or visual disturbance. ${ }^{1-4}$ Though multiple lesions have been reported in the same orbit ${ }^{12}$ we have traced only two reports of cavernous haemangiomas in both orbits. ${ }^{56}$ We report the first case of histologically confirmed bilateral multiple cavernous haemangiomas of the orbit.

\section{Case report}

A 41-year-old Caucasoid woman noted a mass in the medial aspect of her right lower lid, in her late twenties. A plastic surgeon removed the lesion from her anterior orbit. Seven years later a violaceous lump in her left lower lid was also removed. Pathological examination of these lesions showed both to be typical cavernous haemangiomas.

Over the past 14 months she developed left proptosis, with intermittent swelling of the lower lid associated with a blue discoloration of the overlying skin (Fig 1). The swelling did not alter with changes in posture. She had no pain at any stage, and there were no associated visual symptoms. She was referred to one of us (JEW) for further evaluation.

Ophthalmic examination revealed a best corrected visual acuity of $6 / 9 \mathrm{OD}$, attributed to amblyopia, and $6 / 6 \mathrm{OS}$. There was $5 \mathrm{~mm}$ of left axial proptosis, and the left globe was displaced downwards $3 \mathrm{~mm}$. Two small firm pea-sized masses were palpable, one on the anterior edge of the inferior orbital margin of the right orbit, and anteroinferior part in the left orbit. The rest of her ophthalmic examination was normal.

Computed tomography (CT) showed the orbits to be of normal size, although the right superior orbital fissure was bigger than the left. There was about $4 \mathrm{~mm}$ proptosis on the left. More than 20 small, rounded masses were seen in relation to the orbit, varying in diameter from 3

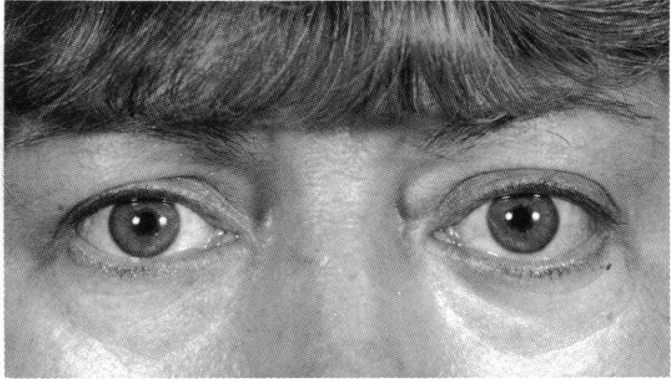

Figure 1 Clinical photograph showing left proptosis and the left lower eyelid swelling.

to $12 \mathrm{~mm}$ (Fig 2). Most of the retrobulbar lesions were intraconal, but similar masses were seen inferior to the globe, in the lids, and in the inferior orbital fissure. One relatively large lesion was contoured to the posteroinferior surface of the globe below the macula, and many lay along the optic nerve. At least 10 similar masses were present in the right orbit, predominantly anteriorly, below the globe. The rounded masses showed variable contrast enhancement. The superior ophthalmic veins were not adequately demonstrated, but the cavernous sinuses were normal. The appearances were considered typical of orbital varices.

Intra-arterial digital subtraction angiography was carried out with injections into the left common, internal, and external carotid arteries (Fig 3). This showed small areas of pooling of contrast medium alongside the globe (supplied by the internal carotid) and posterosuperiorly in the orbit and overlying the maxilla (supplied by the external carotid). The left superior ophthalmic vein was not visualised.

A diagnosis of orbital varices was made and it was decided to remove the anterior component of the vascular anomaly in the left orbit. At operation three $10 \mathrm{~mm}$ diameter, discrete, raspberry coloured masses were removed from the extraconal fat of the inferior orbit.

Pathological examination revealed that al specimens had a similar appearance: wide, endothelial lined, blood-filled channels separated by fibrous trabeculae containing smooth muscle cells and surrounded by a capsule (Fig 4). The features were typical of cavernous haemangiomas.

\section{Discussion}

Cavernous haemangioma has been described as 


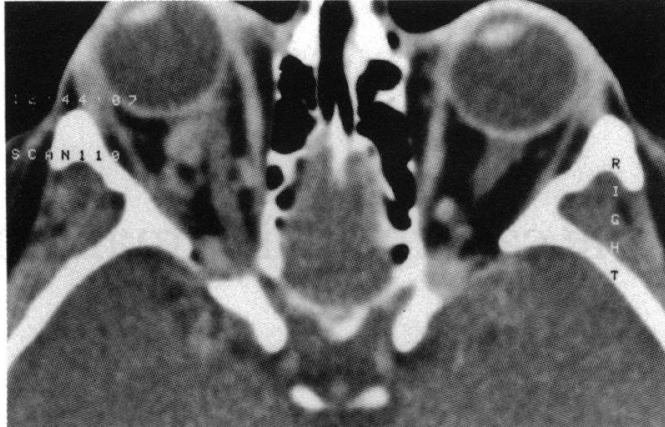

Fig $2 A$

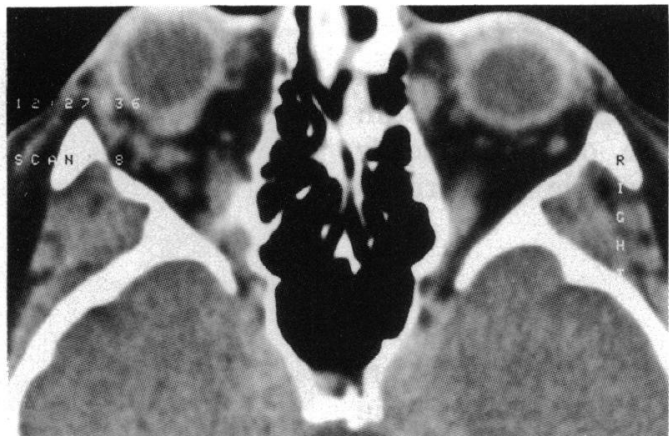

Fig $2 B$

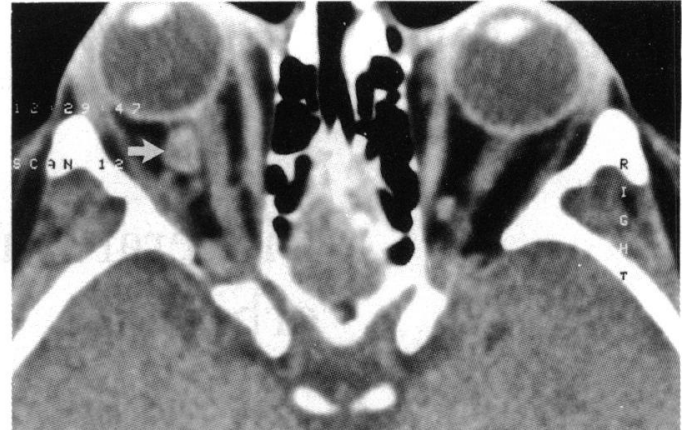

Fig $2 C$

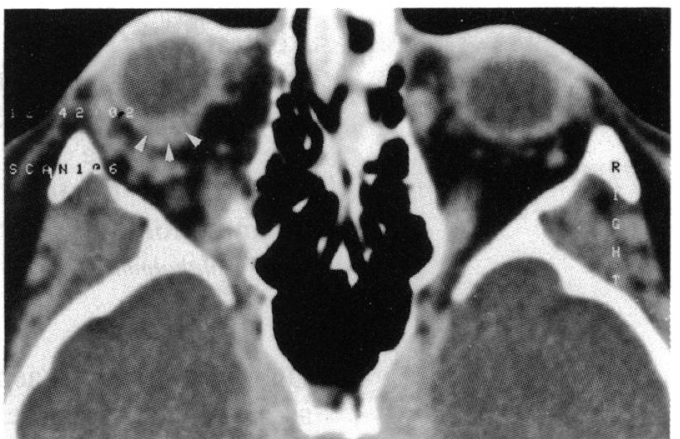

Fig $2 D$

Figure 2 Axial $C T(A, B)$ before $(C, D)$ after intravenous contrast medium. Innumerable rounded or lobulated masses, 2-8 mm in diameter, lie in the retrobulbar spaces and surround the globes. One of the largest (arrowheads) is moulded to the posteroinferior surface of the left globe, while another (arrow) causes medial kinking of the distal portion of the left optic nerve. There is left proptosis.

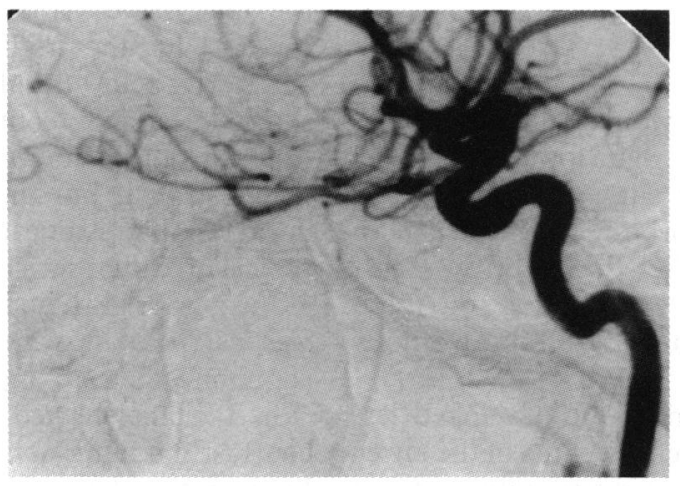

Fig $3 A$

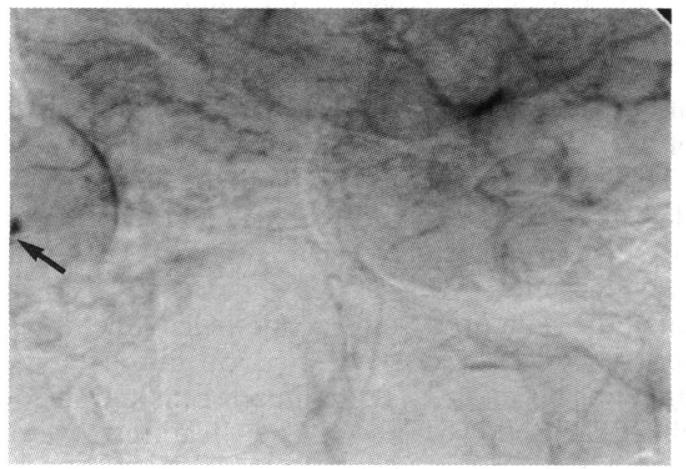

Fig $3 B$

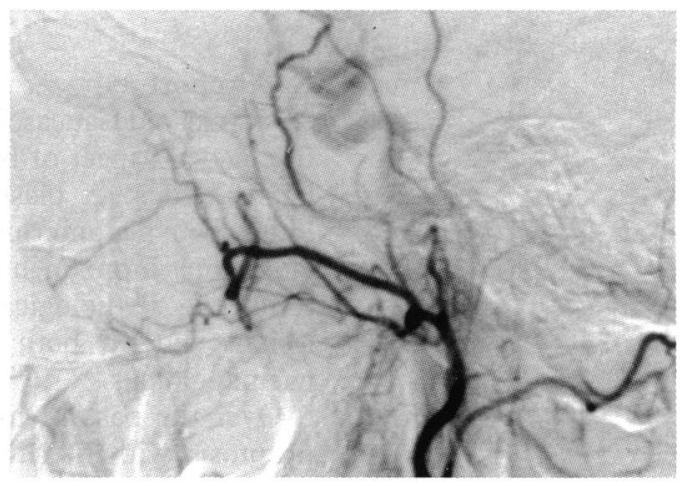

Fig $3 C$

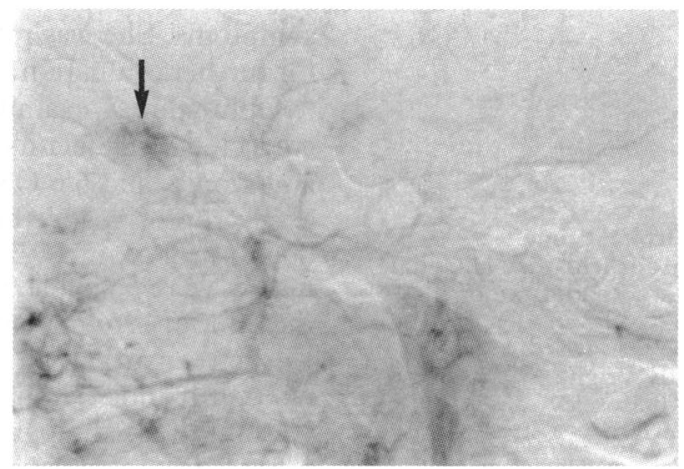

Fig $3 D$

Figure 3 Digital subtraction angiogram, lateral projection (anterior to left). (A,B) Arterial and venous phases of left internal carotid and $(C, D)$ similar phases of external carotid injection (with flash filling of internal carotid) show different small areas of 


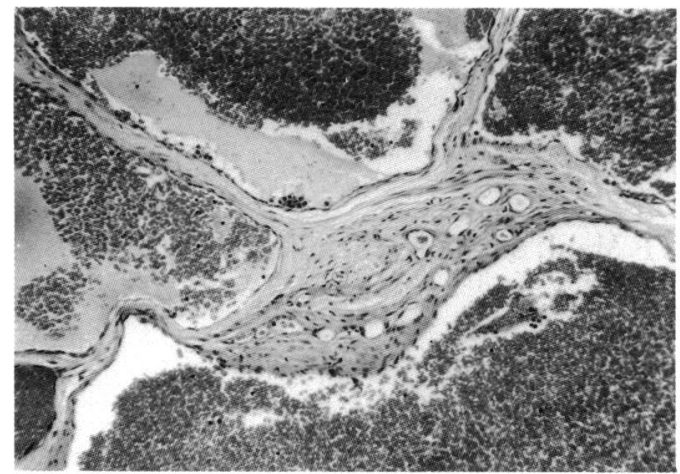

Figure 4 Histological appearance of the haemangioma removed from the left orbit, showing large blood filled channels separated by fibrous trabeculae. Frequently as here, the trabeculae are infiltrated by clusters of small capillaries (haematoxylin and eosin, $\times 80$ ).

the most common orbital tumour. ${ }^{7-9}$ The four principal reviews of cavernous haemangioma describe multiple lesions in the one orbit in none of six, ${ }^{3}$ one of $13,{ }^{4}$ two of $66,{ }^{10}$ and five of 85 patients.' No cases of bilateral cavernous haemangiomas were seen in any of these large series, although two cases of presumed bilateral cavernous haemangiomas have recently been reported. Fries and Char obtained a tissue diagnosis from one orbit but did not operate on the contralateral orbit because of the paucity of symptoms on that side. ${ }^{5}$ Johnson et al presumed a diagnosis of bilateral cavernous haemangiomas on clinical, ultrasonographic, and radiological grounds without obtaining tissue from either orbit. ${ }^{6}$

Our patient had an unusual history with multiple lesions, variable and intermittent lower lid swelling, as well as skin discoloration. Harris and Jakobiec reported one patient who had recurrent spontaneous upper lid ecchymosis. ${ }^{10}$

CT typically shows cavernous haemangiomas as well-defined rounded intraconal masses with smooth contours, of similar density to that of brain, which displace normal structures and enhance with intravenous contrast medium. ${ }^{1112}$ The differential diagnosis on CT includes peripheral nerve sheath tumours, ${ }^{13}{ }^{14}$ and rare lesions such as fibrous histiocytoma $a^{1+15}$ or haemangiopericytoma. ${ }^{+}$The clinical, CT, and angiographic features in our patient were suggestive of primary orbital varices; the ophthalmologist should be aware of this variant.

It was not until surgery that the possibility of multiple cavernous haemangiomas arose. It is not clear why these characteristically unilateral, solitary lesions should have been multiple in both orbits in our patient. An association with Maffucci's syndrome (characterised by multiple enchondromas, soft tissue haemangiomas, and a generalised predisposition to neoplasia) and presumed bilateral orbital cavernous haemangiomas has been made. ${ }^{6}$ But neither in our patient, nor that reported by Fries and Char, were there other stigmata of this disorder.

Mr Sullivan's work is supported in part by the RACO/OPSM fellowship.

$1 \mathrm{McNab}$ AA, Wright JE. Cavernous haemangiomas of the orbit. Aust NZ F Ophthalmol 1989; 17: 337-45.

2 Harris GJ, Jakobiec FA. Cavernous hemangioma of the orbit. In: Jakobiec FA, ed. Ocular and adnexal tumours. Birmingham: Aesculapius, 1978: 741-81.

3 Kopelow SM, Foos RY, Straatsma BR, Hepler RS, Pearlman JT. Cavernous hemangioma of the orbit. Int Ophthalmol Clin 1971; 11: 113-24.

4 Ruchmann MC, Flanagan J. Cavernous hemangiomas of the orbit. Ophthalmology 1983; 90: 1328-36.

5 Fries PD, Char DH. Bilateral cavernous haemangiomas. $\mathrm{Br} \mathcal{F}$ Ophthalmol 1988; 72: 871-3.

6 Johnson TE, Nasr AM, Nalbandian RM, Cappelen-Smith J. Enchondromatosis and hemangioma (Maffucci's syndrome) with orbital involvement. Am f Ophthalmol 1990; 110: 153-9.

7 Forrest AW. Intraorbital tumours. Arch Ophthalmol 1949; 41: 198-232.

8 Moss HM. Expanding lesions of the orbit. A clinical study of 230 consecutive cases. Am 7 Ophthalmol 1962; 54: 761-70.

9 Reese AB. Tumours of the eye, 2nd ed. Hagerstown: Harper and Row, 1976.

10 Harris GJ, Jakobiec FA. Cavernous hemangioma of the orbit. INeurosurg 1979; 51: 219-28.

11 Moseley IF, Sanders MD. Computerised tomography in neuroophthalmology. London: Chapman and Hall, 1982: 53-5.

12 Ruchman MC, Stefanyszyn MA, Flanagan JC, Gonzalez CF Becker MH. Orbital tumors. In: Gonzalez CF, Becker MH, Flanagan JC, eds. Diagnostic imaging in ophthalmology. Flanagan JC, eds. Diagnostic

13 Dervin JE, Beaconsfield M, Moseley IF, Wright JE. CT findings in orbital tumours of nerve sheath origin. Clin Radiol 1989; 40: 475-9.

14 Shields JA, Shields CL, Eagle RC. Cavernous hemangioma of the orbit. Arch Ophthalmol 1987; 105: 853

15 Jacomb-Hood J, Moseley IF. Fibrous histiocytoma of the orbit: computed tomographic findings in ten cases and review of radiological findings. Clin Radiol 1991; 43: $117-20$. 